\title{
O DUPLO NA CONSTRUÇÃO DOS ESPAÇOS INSÓLITOS EM A MORTALHA DE ALZIRA, DE ALUÍSIO AZEVEDO
}

\author{
THE DOUBLE IN CONSTRUCTION OF UNUSUAL SPACES \\ IN A MORTALHA DE ALZIRA, BY ALUÍSIO AZEVEDO
}

\section{Flamilla Pinheiro Costa ${ }^{1}$ \\ Naiara Sales Araujo ${ }^{2}$}

\begin{abstract}
Resumo: O presente trabalho tem como objetivo analisar o efeito do duplo em narrativa fantástica, evidenciando como sua configuração define os efeitos de sentido gerados por meio dessa narrativa e a partir daí cria os espaços insólitos. Em A Mortalha de Alzira (1894), os efeitos ocasionados pelo Duplo - que são vivenciados pelo personagem Ângelo - originam uma confrontação do real com o sobrenatural, construindo, então, os espaços extraordinários na ficção. Esses espaços são os responsáveis pela hesitação e ambiguidade existentes na trama, assim como também são essenciais para questionar as facetas ocultas do homem e sua relação com a sociedade. Para o alcance dos objetivos ora propostos, lançaremos mão dos estudos do escritor e crítico literário espanhol David Roas (2014), da análise crítica sobre as vertentes do Insólito, de Flávio Garcia (2012), e das análises dos locais insólitos, de Filipe Furtado (1980) e Bachelard (2008).

Palavras-chave: Espaços insólitos. Aluísio Azevedo. Duplo. A Mortalha de Alzira.
\end{abstract}

Abstract: This article aims to analyze the effect of the double in fantastic narrative, highlighting how its configuration defines the meaning effects generated through this narrative and giving origin to the unusual spaces. In A Mortalha de Alqira (1894), the effects caused by the Double that are experienced by the character Ângelo - create a confrontation between the real and the supernatural, thus constructing the extraordinary spaces in fiction. These spaces are responsible for the hesitation and ambiguity existing in the plot, as they are also essential to question the hidden facets of man and his relationship with society. For the analysis of this article, we will use the studies of Spanish writer and literary critic David Roas (2014), of the critical analysis on the aspects of the Unusual, by Flávio Garcia (2012), and the analysis of the unusual spaces, by Filipe Furtado (1980) and Bachelard (2008).

Keywords: Unusual spaces. Aluísio Azevedo. Double. A Mortalha de Alzira.

\section{Introdução}

O presente artigo foi concebido a partir do interesse pela análise de obras fantásticas brasileiras, principalmente as escritas por autores maranhenses. Ao analisar a obra do escritor Aluísio Azevedo, conhecido principalmente pelas obras O Cortiço (1890) e O Mulato (1881) - sendo a última considerada a obra fundadora do naturalismo brasileiro -, notamos a necessidade de estudar os seus romances e contos que possuem características do gênero fantástico. Para dar início ao estudo das obras do escritor, analisaremos $A$ Mortalha de Alzira, romance de folhetim publicado

\footnotetext{
${ }^{1}$ Especialista em Cultura e Literatura pela Universidade Braz Cubas (Mogi das Cruzes/SP). Pesquisadora na UFMA. E-mail: flahpinheiro@hotmail.com; http://lattes.cnpq.br/7828501098297589

2 Doutorado em Literatura Comparada pela Universidade Metropolitana de Londres. Professora da Universidade Federal do Maranhão. E-mail: naiara.sas@gmail.com. https://orcid.org/0000-0002-9362-559X; http://lattes.cnpq. $\underline{\mathrm{br} / 6546941294458117}$
} 
em 1894, que foi fortemente inspirado na novela fantástica La morte amoureuse (1836), do escritor francês Théophile Gautier.

Nessa obra, o fantástico é representado de diversas maneiras. Contudo, por ora analisaremos a temática relacionada à duplicidade, que em narrativas literárias é frequentemente identificada. Tal escolha se justifica por ser este um tema abordado desde a Antiguidade, mas que ao longo dos séculos tem ressurgido com novas reflexões.

De acordo com o psicólogo, psicanalista e escritor austríaco Otto Rank (2013, s.p), “o duplo simboliza um sujeito que se vê cindido em dois, movidos por forças antagônicas que lutam internamente e podem levá-lo à autodestruição". Em obras literárias, essas forças são percebidas através dos dois espaços principais da trama: o mundo real e o mundo criado a partir dos sonhos.

Em A Mortalha de Alzira (1894), evidenciaremos como o duplo gerou espaços insólitos e, para tanto, utilizaremos os estudos sobre as vertentes do Insólito, de Flávio Garcia (2012) e Todorov (2007), apresentaremos os conceitos do duplo, de acordo com os estudiosos Rank (2013) e Keppler (1976), e analisaremos os ambientes produzidos, por meio do estudo dos espaços em foco, desenvolvido por Filipe Furtado (1980) e Bachelard (2008).

\section{O duplo nas narrativas fantásticas}

Antes de adentrarmos nos conceitos relacionados ao duplo, é necessário que compreendamos a origem da literatura fantástica, corrente literária que surgiu na segunda metade do século XVIII, em plena ascensão do movimento romântico, sendo o gênero utilizado para quebrar regras rígidas do classicismo e levar o homem a explorar sua imaginação, de modo a libertá-lo das amarras existentes e impostas pela sociedade da época. Assim, a literatura fantástica foi posta em paralelo ao romantismo e ambos se opuseram às correntes racionalistas e iluministas da época. Sobre esse gênero literário, o escritor italiano Ítalo Calvino afirma que:

É no terreno específico da especulação filosófica entre os séculos XVIII e XIX que o conto fantástico nasce: seu tema é a relação entre a realidade do mundo que habitamos e conhecemos por meio da percepção e a realidade do mundo que mora em nós e nos comanda (CALVINO, 2004, p. 9)

Por muitos anos, a literatura fantástica foi utilizada como termo para designar diversos tipos de narrativas e fenômenos que fugiam de explicações racionais e que envolviam elementos como o sobrenatural, o medo e o terror, sendo muitas vezes confundida e entrecruzada com a literatura gótica, em razão de ambas terem sido fortalecidas no período do Romantismo. De acordo com a pesquisadora brasileira Camarani (2014, p. 7),

(...) a narrativa fantástica caracteriza-se ao mesmo tempo pela aliança e pela oposição que estabelece entre as ordens do real e do sobrenatural, promovendo a ambiguidade, a incerteza no que se refere à manifestação dos fenômenos estranhos, insólitos, mágicos, sobrenaturais.

É inegável que o fantástico herdou da literatura gótica muitos dos seus símbolos, e do movimento romântico a necessidade de questionar a visão racionalista. Por conta da quantidade de desdobramentos gerados pelas narrativas fantásticas, ao longo do tempo a análise desse gênero possibilitou a realização de diversos estudos com o intuito de definir o que de fato é a literatura fantástica.

A partir da década de 1970, através dos estudos de Tzvetan Todorov, estabeleceu-se uma maior diferenciação entre o fantástico e outros gêneros, pois até então eram frequentemente compreendidos como indissociáveis, como o maravilhoso e o estranho, por exemplo. Para Mello (2012, p. 94, apud TODOROV, 1975, p. 25), "o fantástico é a hesitação vivida por um indivíduo que conhece apenas as leis da natureza ao se deparar com um evento sobrenatural", ou seja, corresponde ao momento em que uma questão sem resposta racional e imediata surge, provocando

https://periodicos.unifap.br/index.php/letras

Macapá, v. 9, n. 2, $2^{\circ}$ sem., 2019 
nos personagens (e nos leitores) uma dúvida.

Além de conceituar o termo, Todorov (2012) também se preocupou em estabelecer os temas relacionados ao fantástico, dividindo-os em duas categorias: os temas alusivos ao $\mathrm{en}$, que possuem características delimitadas entre a matéria e o espírito; e os temas concernentes ao $t u$, especificados pela sexualidade. Tais temas, vale ressaltar, geram uma ruptura com as questões da realidade, além de estabelecerem uma diferenciação acerca da percepção do tempo e do espaço. "Se quisermos interpretar os temas do tu (...) deveremos dizer que se trata preferentemente da relação do homem com seu desejo e, por isto mesmo, com seu inconsciente" (TODOROV, 2012, p. 148).

É pertinente ressaltar que o tema do tu se desenvolveu em torno de assuntos considerados tabus naquela época - e que persistem nos dias atuais -, encaixando-se a um dos propósitos do fantástico: o de romper a visão de mundo da sociedade daquele tempo. Nesse sentido, geralmente os conteúdos desenvolvidos estavam associados à sexualidade, ao homossexualismo, ao desejo pela mulher proibida, além de outros assuntos considerados proibidos devido à influência da Igreja Católica. Em A Mortalha de Alzira, por exemplo, a temática do tu é observada através do amor e do desejo entre um padre e uma cortesã, ou seja, uma paixão proibida, que por sua vez dá causa aos elementos fantásticos presentes na obra que será analisada mais adiante.

Em seu livro A literatura fantástica: caminhos teóricos (2014), a pesquisadora brasileira Ana Luiza Silva Camarani faz reflexões críticas sobre os caminhos percorridos pela literatura fantástica ao longo dos anos e os seus principais teóricos. Um dos estudiosos analisados pela autora é o português Filipe Furtado. De acordo com a estudiosa, Filipe Furtado, em sua obra $A$ construção do fantástico na narrativa (1980), dá continuidade aos estudos de Todorov e propõe que o fantástico, o maravilhoso e o estranho sejam agrupados como "literatura do sobrenatural", criando, a partir daí uma subdivisão dentro do fantástico tradicional, que passou a ter duas tendências:

(...) enquanto alguns textos se mostram bastante sutis em relação ao sobrenatural, o qual é expresso muitas vezes por meio de uma linguagem poética que intensifica a ambiguidade, outros enfatizam certos componentes oriundos do gótico, dirigindo seus textos para a narrativa de terror. (CAMARANI, 2014, p. 109)

Por meio dessa reflexão, podemos observar alguma coisa dos caminhos percorridos pela literatura fantástica e como seus elementos frequentemente se confundem ou são complementados por características de outras vertentes, como por exemplo o gótico, que proporciona uma imagem de "literatura do sobrenatural" aos textos fantásticos, criando uma atmosfera de dúvida que deve ser considerada ao se analisar os componentes desse tipo de literatura.

Em seus estudos, Filipe Furtado retoma os elementos apontados por Todorov e os sistematiza, organizando e considerando a narrativa fantástica como um gênero literário. Para ele, "um ponto de equilíbrio entre a aceitação ou a recusa da manifestação meta-empírica é extremamente difícil de atingir e, sobretudo, manter até o termo da intriga" (FURTADO, 1980, p. 41). Nesse viés, vale destacar que a intriga, presente no gênero fantástico, é peça importante no desenvolvimento do sobrenatural, assim como a ambiguidade, que possui o papel fundamental de levar o leitor ao limiar entre o real e o imaginário, elementos essenciais desse tipo de narrativa.

Outro pesquisador importante para os estudos da literatura fantástica analisado por Camarani (2014) foi o professor e crítico espanhol David Roas, que concebe a literatura fantástica como um fenômeno da expressão humana. $\mathrm{O}$ autor trata da relação entre o real e o fantástico, ou seja, da correspondência do possível com o impossível, buscando os limites do imaginário e seus efeitos emocionais e psicológicos no personagem e nos leitores, os quais lhe conferem uma categoria estética multidisciplinar.

Para David Roas (2014, p. 31), “a narrativa fantástica põe o leitor diante do sobrenatural [...] para interrogá-lo e fazê-lo perder a segurança diante do mundo real”, quer dizer, é necessário que o fantástico se contraponha ao real para que exista. Por outro lado, sem o elemento sobrena- 
tural o fantástico não pode existir. Esse desdobramento entre o sobrenatural e o fantástico, portanto, é essencial para que o leitor se posicione diante da dúvida do que é real e do que não é.

À medida que o fantástico se desenvolveu como gênero literário, questões além do sobrenatural foram compondo suas narrativas. Assim, cientistas desorientados, loucos, monstros, criminosos e os duplos (ou doppelgängers) não só surgiram como passaram a ser frequentes nas tramas fantásticas, particularizando alguns tipos de narrativas. Dentre esses elementos, iremos destacar a duplicidade, que embarca no interior do homem, fazendo uma relação com o funcionamento da mente humana e, muitas vezes, transgredindo entre dois mundos.

O duplo, podemos dizer, é uma espécie de alter ego que a pessoa possui ao longo da vida, sendo assim, não se limita a ser uma cópia, ao contrário, passa a exercer um papel de realidade. Em outros termos, [...] "o duplo é um mito que acompanha o homem desde que ele tomou consciência da morte. Diante dela, a ausência por excelência, o homem se depara com a falta que atuará na formação do duplo”. (CARREIRA, 2009, p. 49, apud MORIN, 1979, p. 104)

A dualidade é um desdobramento do indivíduo e apesar de ter uma existência muitas vezes autônoma, não perde a sua essência de imitação, de sombra. De acordo com França (2009, p. 8), o duplo

[...] tem sua origem em um indivíduo, do qual é uma espécie de mimesis, mas não possui o mesmo estatuto. Afinal, no momento em que é gerado, já não pode mais ser confundido como o "eu" original; possui uma essência própria e se assume necessariamente como "outro".

Como dito anteriormente, o tema da duplicidade subsiste desde a Antiguidade, aparecendo através das máscaras utilizadas por homens nos teatros medievais, para representar diferentes papeis sociais. Há também os casos em que esse tema surge apenas como uma sombra, um fantasma ou o reflexo do "eu" em "outro", sendo uma personificação do sujeito, ou melhor, o desdobramento do "eu" inicial.

O psicanalista Otto Rank foi o primeiro estudioso a embarcar na investigação dos doppelgängers no cinema e na literatura. Em sua obra "O Duplo", publicada em 1914, o autor faz uma análise desse elemento a partir de filmes, romances e até crenças e narrativas populares de povos primitivos, a fim de encontrar a essência desse fenômeno e explicitar as razões que justificam a sua utilização nas artes. Apesar de sua obra representar apenas um pontapé inicial no que concerne a essa temática - tanto que não foi incisiva a ponto de a crítica começar a se debruçar - certamente serviu de embasamento para que Freud pudesse desenvolver o tema e chamar atenção para a relação entre o estranho e o duplo:

\footnotetext{
Assim, temos personagens que devem ser considerados idênticos porque parecem semelhantes, iguais. Essa relação é acentuada por processos mentais que saltam de um para outro desses personagens pelo que chamaríamos telepatia -, de modo que um possui conhecimento, sentimento e experiência em comum com o outro. Ou é marcada pelo fato de que o sujeito identifica-se com outra pessoa, de tal forma que fica em dúvida sobre quem é o seu eu (self), ou substitui o seu próprio eu (self) por um estranho. Em outras palavras, há uma duplicação, divisão e intercâmbio do eu (self). E, finalmente, há o retorno constante da mesma coisa, a repetição dos mesmos aspectos, ou características, ou vicissitudes, dos mesmos crimes, ou até dos mesmos nomes, através das diversas gerações que se sucedem (FREUD, s/d, p. 16)
}

Décadas depois, o crítico literário norte-americano Carl F. Keppler (1972) fez um levantamento literário sobre o duplo na literatura dos séculos XVIII até o século XX e apontou suas sete representações: o perseguidor, o gêmeo, o (a) bem-amado (a), o tentador, a visão de horror, o salvados e o duplo no tempo. O duplo, vale ressaltar, também é utilizado com a finalidade de ser cômico, através de sósias, gêmeos e identidades duplicadas, sendo encontrado dessa maneira em obras de Shakespeare, Corneille, Molière, entre outros autores.

Nas narrativas de cunho fantástico, o encontramos principalmente em obras como Der 
Sandmann, de E. T. A Hoffman, Frankenstein, de Mary Shelley, The Picture of Dorian Gray, de Oscar Wilde, The Story of the late Mr. Elvesham, de H. G. Wells, entre outros. Uma de suas características mais marcantes está no antagonismo que ele representa, podendo ser apresentado sob a forma do bem e do mal, do racional e do selvagem, do santo e do profano. De acordo com Rodrigues (1988, p. 44),

Variam as formas de representação do duplo: temos personagens que, além de semelhantes fisicamente (ou iguais), têm sua relação acentuada por processos mentais que saltam de um para o outro (telepatia), de modo que um possui conhecimento, sentimentos e experiência em comum com o outro. Ou seja, o sujeito identifica-se de tal modo com outra pessoa que fica em dúvida sobre quem é o seu eu.

De forma psicológica ou física, o sósia pode aparecer em uma única personagem, que se apresenta de forma projetada em uma segunda, ou um outro, que corresponda de forma antagônica a um primeiro. Nessa segunda manifestação, geralmente o perfil do sósia é completamente oposto ao do indivíduo original, existindo apenas certos pontos incomuns que os unem. Na narrativa de Aluísio Azevedo, A Mortalha de Alzira, o duplo, além de gerar uma forma antagônica, também gera um espaço antagônico.

Oromance, influenciado por La morte Amoureuse, de Théophile Gautier, conta a história do padre Ângelo. Adotado quando ainda era bebê pelo frei Ozéas, Ângelo é criado como filho da igreja e educado dentro dos preceitos religiosos, entre paredes de um mosteiro e afastado de toda a luxúria e pecado do mundo exterior - a história se passa na França e retrata a vida boêmia da época. Na tentativa de criar um ser imaculado, Ozéas sufoca o menino exageradamente com todas as suas regras religiosas e não o faz conhecer ninguém fora do monastério, alojando o jovem em uma cela escura e o imergido em textos de caráter religioso. Ao conhecer Alzira em uma missa ministrada para toda a corte francesa, Ângelo começa a ter desejos pela moça e, após a morte dela - e devido a sua paixão reprimida por motivos religiosos; acaba tendo encontros românticos com ela a partir do mundo onírico, onde um outro Ângelo surge: o seu outro.

Sendo assim, em A Mortalha de Alz̧ira, além de uma manifestação psicológica, a duplicidade proporciona ao personagem a criação de um novo mundo, onde não existe o fruto proibido, aquele no qual ele possa desfrutar de Alzira com a sua verdadeira essência. Desse modo, além de proporcionar um reflexo do outro, o duplo também é capaz de gerar efeitos no espaço.

Chamamos de topoanálise, o estudo do espaço nas obras literárias. Segundo Bachelard (1993, p. 20) "a topoanálise seria então o estudo psicológico dos locais de nossa vida íntima". Contudo, podemos absorver mais do que apenas um viés psicológico dentro de um ambiente; encontramos também abordagens essenciais, como as históricas e as sociológicas, que ajudam o leitor a estruturar a narrativa e se conectar com a trama.

Por essa razão, podemos afirmar que o ambiente não é apenas um plano cujo objetivo é caracterizar um personagem ou as paisagens percebidas; é também uma forma de revelar as práticas ideológicas de uma determinada sociedade e mostrar os sentidos (sejam eles ideológicos ou sociais) que a obra intenciona evidenciar ao leitor. Em A Mortalha de Alizira, por exemplo, conseguimos embarcar no alter ego de Ângelo por meio da atmosfera criada nos seus sonhos, o que nos direciona a perceber o eu reprimido do personagem decorrente de razões sociais e religiosas que o cercavam.

E tudo aquilo nunca lhe pareceu tão miserável, tão ermo e turvo, como naquele instante. Aquela dura prisão, onde surdamente se escoara a triste mocidade, nunca lhe pareceu tão árida e tão mesquinha. Aquelas nuas paredes, empalidecidas pelo tempo, nunca lhe pareceram tão apertadas, e aquele sombrio teto, tão baixo e tão sufocante. (AZEVEDO, 2013, s.p)

De acordo com Gama-Khalid (2012, apud FURTADO, 1980), um dos principais elementos que causam a hesitação do leitor perante o mundo que lhe é apresentado é a maneira como os locais são organizados e descritos na narrativa. "Nesse sentido, acreditamos que a configuração 
dos espaços ficcionais define em grande escala a densidade dos efeitos de sentido gerados pela narrativa fantástica, de forma a torná-la mais aberta e plural" (GAMA-KHALID, 2012, p. 32).

Portanto, ter uma ampla percepção de um ambiente possibilita a compreensão da atmosfera em que os personagens se inserem e dos elementos que compõem o desenvolvimento da narrativa. Para entender como um lugar é importante no desdobramento dos personagens em uma narrativa, precisamos entender o que diz o geógrafo humanista Yi-Fu Tuan (2004, p.3): "Espaço e lugar são termos familiares que indicam experiências comuns. Vivemos no espaço. (...) O lugar é segurança e o espaço é liberdade: estamos ligados ao primeiro e desejamos o outro". Destarte, o lugar é, pois, onde situamos os personagens e suas ações, ao passo que o espaço denota movimento.

$\mathrm{Na}$ obra em questão, o ambiente possui um papel fundamental na vida de Ângelo, pois proporciona a liberdade não vivida pelo protagonista em virtude da sua vida religiosa. Assim, diante da ausência de um lugar e de um espaço real que lhe possibilite desfrutar do seu amor, o padre cria um ambiente insólito, representado pelo onírico, que por sua vez lhe dá uma liberdade que não possui.

A esse respeito, no livro A Casa \& A Rua: espaço, cidadania, mulher e morte no Brasil (1997), Roberto DaMatta (1997, p. 29) afirma: "O espaço é como o ar que se respira. Sabemos que sem ar morreremos, mas não vemos nem sentimos a atmosfera que nos nutre de força e vida. Para sentir o ar é preciso situar-se, meter-se numa certa perspectiva”. Na obra, Alzira - logo após a sua morte - aparece nos sonhos de Ângelo para "resgatá-lo" e juntos viverem em um novo mundo, com o amor e os prazeres de que foram privados.

Para o antropólogo e filósofo Gilbert Durand (2000), a não aceitação da morte auxilia na criação de um elemento "imaginário". Em seu livro A imaginação simbólica, desenvolve a ideia de que, com a angústia da morte e do devir, o homem toma atitudes com o intuito de negá-la, superando o óbito e transformando-o, ou seja, invertendo seu significado em algo mais reconfortante. Tais sentimentos permeiam a duplicidade existente em Ângelo, uma vez que este passa o dia contando as horas para que chegue o momento da noite, quando ele finalmente pode se debruçar nos braços da sua amada. É importante asseverar que o fato de o sacerdote preferir a noite para expressar o seu duplo também é fator importante para a análise dos espaços insólitos da narrativa. De acordo com Durand (2000, p. 110):

Para os egípcios, o céu noturno, assimilado ao céu de baixo, manifesta explicitamente o processo de inversão: uma vez que este mundo noturno é a exata imagem invertida, como que num espelho, do nosso mundo. (...) Este processo é ainda mais nítido nos tungus e nos koriak, para os quais a noite é o dia do país dos mortos, uma vez que tudo está invertido neste reino noturno. "O mundo dos mortos", escreve Lewitzki, "é, de algum modo, a contrapartida do mundo dos vivos", o que é suprimido na terra reaparece no mundo dos mortos.

Então, Ângelo, que não imagina mais sua vida sem Alzira desde que descobriu a sua existência, lança mão de um mundo fantasioso, o qual vê como uma oportunidade de viver o que a vida religiosa não lhe permitia.

- A tua companhia. Venho buscar-te.

-Buscar-me?...

- Sim. Com a força do meu amor, consegui vencer o abismo que nos separava e chegar até aqui. Minha alma foi arrojar-se aos pés de Deus e pedir-lhe, pelo muito que sofri em vida por amar-te em segredo, que lhe concedesse a graça de aparecer-te todas as noites durante o sonho. Deus, apiedado, porque eu te não possuí na vida dos sentidos, consentiu que me pertencesses nesta existência espiritual, melhor que a outra. Aqui me tens, e todas as noites, mal adormeças, eu virei buscar-te. (AZEVEDO, 2013, s.p)

O sonho - tema comum, ainda no Romantismo, principalmente na França -, é o meio utilizado pelo homem para abandonar o mundo real e criar uma válvula de escape, onde possa se 
proteger daquilo que o atormenta e, ao mesmo tempo, sentir-se livre. Freud, em seu livro A Interpretação de Sonhos (1899), desenvolve o tema em questão afirmando que estes correspondem à realização de um desejo. De acordo com a pesquisadora brasileira Giovana Rodrigues da Silva, o imaginário é uma maneira de se desligar do mundo exterior. Para a autora,

[...] o sonho é um exemplo privilegiado de um processo primário, pois é acompanhado de uma diminuição das necessidades físicas e por um desligamento daquilo que possa vir a ser externo. (...) através dele podemos compreender os sintomas, os mitos, as religiões e a obra de arte como expressão do nosso desejo mais íntimo (SILVA, 2012, p. 70).

$\mathrm{Na}$ obra de Aluísio Azevedo, o mundo onírico aparece não apenas como recurso para o insólito, mas também como uma necessidade de vida do personagem. "Às sete horas deitou-se cansado e adormeceu logo, precipitando-se no sonho, como se acordasse da vida" (AZEVEDO, 2013, s.p). Para Monteiro,

[...] o sonho, esse espaço mágico, faz com que, como diria Deleuze (2009), o presente e o passado se intercambiem, apagando as fronteiras entre o real e a fantasia, de tal forma que esses polos opostos se interpenetrem, neutralizadas as diferenças impostas pela vigília racionalista (MONTEIRO, 2012, p. 98).

Os devaneios de Ângelo, dessa forma, funcionam como a sua libertação, não apenas do seu eu físico, mas também do seu eu psicológico, pois é através deles que nos conectamos ao duplo de Ângelo, cheio de luxúria e ávido pelo mundo dos prazeres que lhe são proibidos no mundo real. Ou seja, através desses sonhos e do seu duplo Ângelo coloca em evidência desejos e pensamentos que o mundo real não lhe dá o direito de expressar, devido à sua condição de padre.

De acordo com a psicanalista e pesquisadora Tania Rivera, o imaginário representa pensamentos e ideias abstratas, formando assim desejos do sujeito. Para ela, o sonho é "uma infindável teia de pensamentos, recordações e restos de percepções vividas, e sua interpretação dá origem a sucessivos planos discursivos" (RIVERA, 2011, p.22).

Nesse plano, Alzira é a ponte que liga os dois Ângelos: o santo e o profano. Também é aquela que o encaminha rumo a uma realidade inexplicável e livre. Assim, o duplo acaba por gerar ambientes propícios para o desenvolvimento dos elementos fantásticos da obra.

- Sim! Sim! disse. Eu irei contigo! Quero gozar! Quero viver!

E uma larga estrada maravilhosa abriu-se defronte deles, onde dois negros cavalos, esplendidamente ajaezados, impacientes os esperavam relinchando. (...) Ângelo e Alzira montaram e partiram a galope. (AZEVEDO, 2013, s.p)

Diante do exposto, é possível depreender que o outro eu é revelado ao leitor, e ao próprio protagonista, exatamente pelos onírico, o que corrobora com a visão de Bachelard sobre a relação entre o mundo exterior e o interior, "o jogo entre o exterior e a intimidade não é um jogo equilibrado" (BACHELARD, 2008, p. 19). Daí, a partir desse desequilíbrio entre o eu e o outro, a segunda parte da obra, intitulada O Mundo dos Mortos, ilustra melhor ainda o desenvolvimento do Outro nos espaços.

\section{Os espaços insólitos em A mortalha de alzira}

Antes de analisar os principais locais insólitos presentes na obra e que foram criados a partir da duplicidade do protagonista, é necessário entender o sonho como uma atmosfera ficcional importante para as narrativas fantásticas. $\mathrm{O}$ ato de sonhar é considerado um refúgio da mente humana, onde o ser humano pode resgatar lembranças, sentimentos e até mesmo construir um universo onde possa soltar seus pensamentos mais profundos. Em A Mortalha de Alzira, Ângelo 
anseia por seus momentos oníricos, a fim de que possa desfrutar da riqueza e do desejo que não conseguiu realizar em vida pela sua condição social. $\mathrm{Na}$ trama, o eclesiástico cria um lugar de refúgio, onde ele pode ser o que, de fato, gostaria de ser.

- Também no outro mundo tenho reminiscências de uma vida inteira. Lembro-me do colégio, das férias passadas com parentes, dos afagos de meus pais... sim! Porque lá não sou um miserável enjeitado... tenho família e tenho amigos... É uma vida completa e perfeita! Esta outra existência obscura, de pároco de aldeia, apresenta-se-me então ao espírito como um sonho extravagante e ridículo! (AZEVEDO, 2013, s.p)

De acordo com Bachelard, a casa é o nosso canto no mundo. Nessa perspectiva, o filósofo afirma que:

A casa é uma das maiores (forças) de integração para os pensamentos, as lembranças e os sonhos do homem. Nessa integração, o princípio de ligação é o devaneio. O passado, o presente e o futuro dão à casa dinamismos diferentes. [...] sem ela, o homem seria um ser disperso. Ela mantém o homem através das tempestades da vida. É corpo e é alma. (BACHELARD, 2008, p. 26)

Ângelo não possui um lugar no mundo desde que para ele despertou. Ao conhecer Alzira, acabou questionando sua crença e até mesmo o seu papel na sociedade, passando anos e anos se privando de seus desejos e não dirimindo suas dúvidas sobre o mundo que existe fora daquele que conhece, o da Igreja. Após a morte de Alzira, o sacerdote se sente ainda mais solitário e, através dos seus devaneios noturnos, cria um espaço onde possa ser livre. Ou seja, ele usa o plano do inconsciente como sua casa, "seu lugar no mundo". Esses ambientes possuem vestígios do seu passado e também os seus desejos, angústias e manifestações dos seus pensamentos. Palácios estranhos, penhascos e vales negros, florestas e galerias de pedras são alguns dos ambientes que aparecem no seu inconsciente para representar o mundo onde Alzira vive - o mundo dos mortos -, os quais serão analisados adiante.

Logo no início da sua jornada rumo ao Mundo dos Mortos, a floresta surge como o primeiro terreno com o qual Ângelo tem contato e é descrita como "duas faixas de treva compacta, que se rasgava de vez em quando ao súbito bruxulear dos relâmpagos" (AZEVEDO, 2013, s.p).

Para Durand (2000, p. 214), "a floresta é o centro de intimidade como o pode ser a casa, a gruta ou a catedral. A paisagem silvestre fechada é constitutiva do lugar sagrado. Todo lugar sagrado começa pelo 'bosque sagrado"'. Já no Dictionnaire des Symboles, de Jean Chevalier (1982), encontramos a definição de floresta para diferentes povos. Em diversas regiões, como os dos Celtas, a floresta se constituía em um verdadeiro santuário; um estado da natureza. Mas, de acordo com Chevalier, ela também pode representar a entrada para o inconsciente.

Pour l'analyste moderne, par son obscurité et son enracinement profond, la forêt symbolise l'inconscient. Les terreurs de la forêt, comme les terreurs paniques seraient inspirées, selon Jung, par la crainte des révélations de l'inconscient. (CHEVALIER 3 , 1982, p. 456).

Por esse viés, esta pode ser analisada na obra como a entrada para o duplo de Ângelo, que irá se revelar aos poucos na narrativa, transformando-o em um libertino boêmio. Ou seja, a floresta representa o lado reprimido de Ângelo por conta dos seus ideais morais e religiosos e, ao mesmo tempo, é a porta de entrada para os seus pensamentos, emoções e angústias.

Por mais que seja uma viagem para o mundo dos mortos, o mundo onírico de Ângelo não é considerado como ruim, uma vez que traduz o seu espaço de libertação e de descoberta. "A eles (os espaços das nossas solidões) voltamos nos sonhos noturnos. Esses redutos têm valor de

\footnotetext{
3 Para o analista moderno, por conta da sua obscuridade e do seu enraizamento profundo, a floresta simboliza o inconsciente. Os terrores da floresta, assim como os terrores do pânico seriam inspirados, segundo Jung, pela angústia das revelações do inconsciente. (Tradução nossa)
} 
concha. E, quando vamos ao fundo dos labirintos do sonho, quando tocamos as regiões do sono profundo, conhecemos talvez repousos anti-humanos" (BACHELARD, 2008, p. 29).

Após passar pela porta de entrada do seu santuário particular, a floresta, Ângelo se vê diante de um palácio iluminado por um sinistro luar, com paredes de pedras e longas galerias formadas de caveiras e tíbias. Essa passagem é perturbadora para o personagem, por ser perseguido por sombras silenciosas que o perturbavam; uma clara referência à consciência do seu real, o padre casto.

E só deteve o passo ao chegar a um enorme salão, singularmente ornado de estátuas em esqueleto e iluminado por milhares de piras bruxuleantes. Uma vasta galeria perdia-se ao fundo, multiplicando as colunas a perder de vista. Ao centro um grande órgão, em que velho e carcomido esqueleto, todo vergado sobre o teclado, tocava, com seus movimentos demoradíssimos, uma arrastada harmonia funerária. (AZEVEDO, 2013, s.p)

Para Chevalier, o palácio é um local que representa harmonia por juntar em um só lugar três planos: o subterrâneo, o terrestre e o celestial. Ele também afirma que "le palais ajoute les précisions qu'évoquent la magnificence, le trésor et le secret. Le palais est la demeure du souverain, le refuge des richesses, le lieu des secrets" ${ }^{4}(1982$, p. 723$)$

O palácio, na obra, é uma representação do mundo de Alzira ao qual Ângelo nunca teve a oportunidade de descobrir, dado seu papel social. Em vida, Alzira morava em um grande casarão, onde recebia seus pretendentes e amantes, fazendo assim o seu trabalho de cortesã. Ela recebia apenas quem queria, por isso levava o título de cortesã mais cobiçada de Paris. Ao ilustrar o palácio, Alzira o retrata como a região das amorosas e explica:

Achamo-nos agora em uma das seções da grande região das amorosas; esta é a seção das infelizes que, como eu, prostituíram o corpo na outra vida!... Todas elas vêm ter aqui após o seu passamento, e a cada uma só acompanha o homem que no mundo a amou deveras e foi por ela correspondido. (AZEVEDO, 2013, s.p)

É por essa razão que Ângelo consegue embarcar no palácio, sendo o único homem a quem Alzira amou, e mesmo estando vivo, consegue ter acesso ao mundo dos mortos, ao qual agora sua amada pertence. Além disso, o palácio representa um local com grandes vaidades e luxúrias:

Por toda a parte viam-se, passeando aos pares, espectros de homens e de mulheres; uns com os ossos à mostra, outros envolvidos em longas túnicas sombrias. Aqui declamavam versos de amor, ali carpiam saudades eternas, e todos surdamente e lentamente se agitavam, se confundiam e se baralhavam. (AZEVEDO, 2013, s.p).

Em ambos os espaços descritos acima - e em outros que Ângelo produz no mundo dos seus sonhos -, há um grande número de acontecimentos incomuns que só são possíveis dentro do plano sobrenatural. Um desses acontecimentos é o encontro do Ângelo boêmio, ladrão e assassino com o seu verdadeiro eu, o Ângelo padre e ingênuo. Chega um momento na narrativa em que o real invade o mundo dos sonhos e podemos encontrar, em um mesmo espaço, Ângelo e o seu duplo, para um confronto.

- E que tens tu com isso, hipócrita? Interrogou o Ângelo boêmio, recuperando o sangue frio. Acaso vou eu tomar-te contas das ridículas pantomimices que levas a praticar durante o dia em Monteli?... Interrompo porventura a farsa das tuas missas, quando charlataneias o teu irrisório latim e ergues ao ar, espetaculosamente, dois dedos de vinho e três de obreira proclamando o que é sangue e corpo de

\footnotetext{
${ }^{4} \mathrm{O}$ palácio adiciona as precisões que invocam a magnificência, o tesouro e o segredo. O palácio é a moradia do soberano, o refúgio das riquezas e o local dos segredos. (Tradução nossa)
} 
Cristo? (...) Já fui eu lá insinuar aos teus devotos que os teus milagres são mentira, como é mentira tua fé, como é mentira a tua ciência, como é mentira a tua religião?... Não me venhas, pois, aborrecer, onde não és chamado, e volta para a tua pestilenta aldeia, que tens lá quem precise dos teus desvelos e dos teus conselhos. (AZEVEDO, 2013, s.p)

O confronto acaba em embate físico, que representa o momento em que efetivamente o duplo se encontra, já que após o embate o padre acorda bastante aflito, lutando com a sua própria sombra. "O infeliz vigário acordou afinal, na vida real, banhado de suor, sufocado e aflito, a debater-se no seu leito com a própria sombra, que o estrangulava" (AZEVEDO, 2013, s.p). Então, o limite entre o espaço real e o insólito é quebrado, fazendo com que tanto o leitor quanto Ângelo fiquem confusos sobre o que de fato aconteceu, entregando, assim, a tarefa de desvendar o que respondeu ao ambiente onírico ou a algum acontecimento sobrenatural ao leitor. De acordo com Roger Caillois:

A conivência do sonho e do fantástico é inevitável, pois o sonho, que é sempre misterioso, pode facilmente tornar-se aterrador. Através dele, a pessoa que dorme se imagina introduzida em um mundo sobrenatural ou, ao contrário, alguma coisa de um mundo interdito lhe parece forçar a entrada de sua consciência. (CAILLOIS, 1978, p. 45)

A configuração do Outro constrói o universo misterioso da obra a partir do sonial, que é a base para as atmosferas insólitas. Esses locais são os responsáveis pela hesitação e ambiguidade e é através da análise do que ocorre nesses ambientes que o leitor decide o que de fato é realidade ou não, provando, assim, que os espaços insólitos possuem um papel essencial para o desenvolvimento da duplicidade no fantástico, auxiliando na construção de aspectos narrativos que lhe são inerentes. A utilização de atmosferas insólitas na obra representa uma maneira de isolar o mundo dos sonhos e mostrar ao leitor um lado oculto do padre Ângelo, mediante o desenvolvimento do seu outro eu, o seu duplo.

\section{Considerações finais}

Em A Mortalha de Alzira (1894) há diversos fatores que aproximam a obra a elementos do fantástico e até do gótico. O duplo, certamente, é o mais perceptível e que possui papel essencial para o desenvolvimento da obra. É através desse elemento - tão presente em obras de cunho fantástico - que a narrativa se desenvolve, originando um novo Ângelo, o seu alter ego, aquele que podia usufruir dos prazeres do mundo em outra dimensão, a do ambiente onírico.

Através desse ambiente podemos visualizar, principalmente nessa obra, como o espaço onírico é o responsável pela hesitação e pelas ambiguidades existentes na história, proporcionando elementos espaciais essenciais para que Ângelo questionasse a sua vida como padre.

Como já dito neste estudo, analisar o espaço é uma forma de ver o texto em uma nova perspectiva. Assim sendo, por intermédio das análises dos espaços oníricos da obra podemos visualizar críticas que ultrapassam as diversas facetas não somente do ser humano, mas também da sociedade de um modo geral.

\section{Referências}

AZEVEDO, Aluísio. A Mortalha de Alrira. 1. ed. LL Livrary: 2013 (e-book).

BACHELARD, Gaston. A Poética do espaço. Tradução de Antonio de Pádua Danesi. 2. ed. São Paulo: Martins Fontes, 2008.

- A poética do Espaço. São Paulo: Martins Fontes, 1993.

BATALHA, Maria Cristina. GARCIA, Flávio. Vertentes Teóricas e Ficcionais do Insólito. Rio de Janeiro: Editora Caétes, 2012.

CAILLOIS, Roger. Prestígios e problemas do sonho (a imagem onírica). In: CAILLOIS, Roger; 
GRUNEBAU, G. E. Von. O Sonho e as Sociedades Humanas. Tradução de Júlio Castanõn Guimarães; Rio de Janeiro: Francisco Alvez, 1978. p. 27-50.

CALVINO, Italo (org.). Contos fantásticos do século XIX. Vários autores. Vários tradutores. São Paulo: Companhia das Letras, 2004.

CAMARANI, Ana Luiza Silva. A Literatura Fantástica: caminhos teóricos. São Paulo: Cultura Acadêmica, 2014.

CARREIRA, Shirley de Souza Gomes. A dupla visão do insólito: entre a memória e o esquecimento - o outro pé da sereia, Mia Couto. In: GARCIA, Flavio. Motta, Marcus. O insólito e seu duplo. Rio de Janeiro: EdUERJ, 2009; pág. 47-65.

CHEVALIER, Jean. GHEERBRANT, Alain. Dictionnaire des Symboles. Grande Bretagne: Les Éditions Robert Laffont, 1982.

DAMATTA, Roberto. A casa e a rua. Rio de Janeiro: Rocco, 1997.

DURAND, Gilbert. A imaginação simbólica. Lisboa: Edições 70, 2000.

FEITOSA, Antonio Cordeiro. O conhecimento e a experiência como condição fundamental para a percepção da paisagem. In: ALVES, Ida Ferreira Alves. FEITOSA, Marcia Manir Miguel. Literatura e paisagem: Perspectivas e diálogos. Rio de Janeiro: Editora da UFF, 2010. pág. 31-42.

FRANÇA, Julio. O Insólito e seu duplo. In: GARCIA, Flavio. MOTTA, Marcus. O insólito e seu duplo. Rio de Janeiro: EdUERJ, 2009; pág. 7-14.

FREUD, Sigmund. O estranho.In Obras completas. Rio de Janeiro: Imago, s.d, vol. XVII.

FURTADO, Filipe. A construção do fantástico na narrativa. Lisboa: Livros Horizonte, 1980.

GAMA-KHALID. Marisa. As teorias do fantástico e sua relação com a construção do espaço ficcional. In: BATALHA, Maria Cristina; GARCIA, Flávio.Vertentes Teóricas e Ficcionais do Insólito.Rio de Janeiro: Editora Caétes, 2012; pág. 30-37.

KEPPLER,Carl F.The literature of the second self.Tucson: University of Arizona Press, 1972.

MELLO, Camila. "As Formigas", de Lygia Fagundes Telles: O insólito em cinco atos. In: BATALHA, Maria Cristina; GARCIA, Flávio. Vertentes Teóricas e Ficcionais do Insólito. Rio de Janeiro: Editora Caétes, 2012; pág. 90-96.

MONTEIRO, Maria Conceição. Figurações Obtusas de Sonhos e Fantasias: O duplo e o erótico. In: BATALHA, Maria Cristina; GARCIA, Flávio. Vertentes Teóricas e Ficcionais do Insólito. Rio de Janeiro: Editora Caétes, 2012; pág. 97 -105.

RANK, Otto. O duplo: um ensaio psicanalítico. Porto Alegre: Dublinense, 2013.

RIVERA, Tania. Cinema, Imagem e Psicanálise. $2^{a}$ edição. Rio de Janeiro: Zahar, 2011.

ROAS, David. A Ameaşa do Fantástico. São Paulo: Editora Unesp, 2014.

RODRIGUES, Selma Calasans. O Fantástico. Série Princípios. São Paulo: Ática, 1988.

SILVA, Giovana Rodrigues da. O sonho e a psicanálise freudiana. In: Revista EnsiQlopédia - FACOS/CNEC Osório. v.9 n.1. Out/2012 pág. 70-76.

TODOROV, Tzevetan. Introdução à literatura fantástica. São Paulo: Perspectiva, 2012.

TUAN, Yi-Fu.Espaşo e Lugar: a perspectiva da experiência. Londrina: Eduel, 2013. Londrina: Eduel, 2013.

Envio: 30/10/2019

Aceite: 08/11/2019 